\begin{tabular}{|l|l|}
\hline $\begin{array}{l}\text { Postprint } \\
\text { Version }\end{array}$ & 1.0 \\
\hline $\begin{array}{l}\text { Journal website } \\
\text { Pubmed link }\end{array}$ & $\underline{\underline{\text { http://www3.interscience.wiley.com/journal/123202399/abstract?CRETRY=1\& }}}$ \\
\hline DOI & $\underline{\text { http://www.ncbi.nlm.nih.gov/pubmed/19960548 }}$ \\
\hline
\end{tabular}

This is a NIVEL certified Post Print, more info at http://www.nivel.eu

\title{
The Influence of News Events on Health After Disaster: A Longitudinal Study in General Practice
}

\author{
Petra M.H. TEN VeEn, MATTIJn MORREN, AND C. Joris YZERMANS
}

Netherlands Institute for Health Services Research, Utrecht, The Netherlands

This study investigates the influence of local and international news events on utilization of health services resources and health complaints as presented by victims of a fireworks depot disaster. It was hypothesized that victims $(\mathrm{N}=2,854)$ will show more utilization and health complaints to their general practitioner (GP) in the week after 11 local news reports of events relating to the specific index trauma and 6 unrelated disasters reported in international print news, than the week before. Health data of victims and matched controls were extracted from electronic medical records, covering 4-years postdisaster. Especially local news events concerning the cause of the disaster were associated in both victims and controls with an increase of GP utilization and health complaints, including medically unexplained physical symptoms, chronic diseases, and psychological problems. No difference between victims and controls were found.

When disaster strikes, the media almost immediately brings the news into people's homes worldwide. In some cases, the moments before disaster strikes can even be witnessed; the plane used in the terrorist attacks on the World Trade Center (WTC), for instance, was filmed by amateurs before it actually crashed into the building.

Victims often present health complaints, both psychological and physical, in the aftermath of a disaster (Donker, Yzermans, Spreeuwenberg, \& van der Zee, 2002; Norris et al., 2002; Yzermans \& Gersons, 2002; Yzermans et al., 2005). They may suffer short-term as well as long-term health consequences, such as posttraumatic stress disorder, depression, anxiety, or physical symptoms (Bromet \& Havenaar, 2002; Rubonis \& Bickman, 1991).

Because there are only a few studies about the relationship between seeing, hearing and/or reading news and postdisaster utilization of health services and the presentation of health complaints, we wonder whether people (victims) who were closely involved in a disaster will months or years later experience health complaints while confronted with news events about the index disaster or other (comparable) disasters and to what extent.

In some studies, associations were demonstrated between the news (seeing television coverage of the WTC attacks) and stress symptomatology (Cohen-Silver, Holman, McIntosh, Poulin, \& Gil-Rivas, 2002; Schlenger et al., 2002; Schuster et al., 2001).

Victims directly exposed to the WTC attacks showed a stronger association between watching television images and posttraumatic stress symptoms and depression than those who were not directly exposed to the disaster (Ahern et al., 2002). In another study, Ahern et al. found that chances of posttraumatic stress disorder were more than twice as high in individuals who watched television most often (Ahern, Galea, Resnick, \& Vlahov, 2004). These studies about the WTC attacks all concern short-term effects, using surveys among people involved and not directly involved and reporting self-reported health complaints. 
Not only television viewing may influence people's health, reading disaster-related newspaper stories may do so as well. In the Netherlands, a survey was conducted on the health of people who survived the Bijlmermeer disaster in 1992, when an airplane crashed into two apartments in an Amsterdam suburb, killing 39 residents and four crew members. Six years after the disaster, a strong relationship was found between the number of stories in national Dutch dailies and the number of people-even people with hardly any connection to the disaster itself, but still living in the area-reporting health complaints to their general practitioner (GP) (Vasterman, Yzermans, \& Dirkzwager, 2005; Yzermans, Donker, \& Vasterman, 2003).

Gortner and Pennebaker studied regional newspaper reports after an unexpected collapse of 5,000 logs, killing 12 college students.

When the number of articles decreased after 2 weeks, they found an increase in visits to the local health center (Gortner \& Pennebaker, 2003). This result was never confirmed in other studies.

Finally, Vasterman et al. conducted a review on the role of the media in the context of disasters and their aftermath. They concluded that media may have an important impact on arising health complaints and on how people view their health complaints, but only a few studies have examined associations between the media and health complaints following disasters (Vasterman et al., 2005).

In the present study, the effect of news events (in this case, newspaper stories) on GP utilization and health complaints of victims of a disaster was explored during a period of 4-years postdisaster.

We hypothesized that after major news events victims (a) will respond with more contacts with their GP compared to the week before the event, and (b) will present a higher increase in psychological problems and physical symptoms to their GP compared to the week before.

On May 13, 2000, a fireworks depot exploded in the city of Enschede, in the eastern part of the Netherlands. The explosions and subsequent fire killed 23 people, and over 900 people were injured. About 500 houses were severely damaged or destroyed, and 1,200 people had to be relocated for several years. In the first week after the disaster, hundreds of journalists from all over the world were present near the disaster scene. From the news coverage in following years, we selected local news events concerning the cause of this disaster. International news events regarding other disasters were also selected. Utilization and health complaints of victims of the disaster were determined using data from the GPs' registration systems. The same procedure was carried out for matched controls who lived in the same city but who had not been exposed.

\section{METHOD}

\section{Participants}

In the Dutch health care system every citizen is obliged to be on the list of one GP, who acts as a gatekeeper to secondary care. Each consultation of a patient is registered by the GP in his electronic medical registration system (EMR). All GPs $(\mathrm{N}=60)$ in Enschede were asked to participate in the study: 44 agreed. The other 16GPs (27\%) did not have victims on their list $(n=9)$ or declined due to anticipated increase in workload $(n=5)$ or had a type of electronic medical registration system $(n=2)$ for which data extraction was not feasible. In the GPs' records, patients were marked as a victim of the disaster based on postal code of their home address at the time of the disaster and information on who was a victim by the municipal authorities. From the participating GPs, 9,892 disaster victims were registered (89\% of the number of victims), including a group of 927 people who lived in the immediate neighborhood of the exploded fireworks depot and who had to be relocated because their houses were destroyed. A control group matched on anonymous GP patient records from the participating GPs who were not recorded as victims in the registration system and who did not live in the disaster area $(\mathrm{N}=10,031)$.

From this cohort, a group of victims was selected aged 15 years and older at the time of the disaster who were on the list of participating GPs for the study period of 4-years postdisaster $(\mathrm{N}=2,854)$. At the time of the start of this study, data of 5 years were available, including one year before the disaster. Next, an equally sized control group was matched for age and gender and health insurance. Health insurance was used as an indicator for socioeconomic status (SES). Private health insurance represents a high SES because the individual's income has to be above a certain level, whereas public health insurance represents a low to medium SES. Following the procedures described, the number of persons involved was 5,708. In both groups, more than half were men $(52.2 \%)$, the mean age was 44.2 years $(\mathrm{SD}=17.1)$, and $76.5 \%$ had a low to medium SES. 
Veen, P.M.H. ten, Morren, M., IJzermans, C.J. The influence of news-events on health after disaster: a Iongitudinal study in general practice. Journal of Traumatic Stress: 2009, 22(6), 505-515

\section{Measures}

After each contact with a patient, the GPs electronically registered information on the presented health complaints. They used the International Classification of Primary Care (ICPC; Lamberts \& Wood, 1987), which is compatible with both the International Classification of Diseases (ICD-10; World Health Organization, 1992) and the Diagnostic and Statistical Manual of Mental Disorders,

Fourth Edition (DSM-IV ; American Psychiatric Association, 1994). Using individual ICPC codes would result in rather small numbers. Therefore, we regrouped the ICPC codes in 16 clusters (Yzermans et al., 2005). For instance, the cluster psychological problems consists of ICPC codes representing stress reactions, anxiety, sleeping problems, and depression. Six clusters were used in this study: chronic diseases, psychological problems, respiratory, musculoskeletal, and skin symptoms and diseases, and medically unexplained physical symptoms (MUPS). Medically unexplained physical symptoms are physical symptoms (e.g., tiredness, headache, nausea, and abdominal pain) for which there may be no diagnosis by the GP. The choice for these clusters was based on published reports of increased prevalence of psychological problems and/or physical symptoms after disasters (Donker et al., 2002; Escobar, Canino, Rubio-Stiper, \& Bavo, 1992; Schnurr, Spiro, \& Paris, 2000; Yzermans et al., 2005). Visits of patients for an influenza vaccination were excluded.

After the Enschede fireworks explosion in 2000, newspapers were checked daily for items concerning the disaster and its aftermath.

A news dossier was set up, containing thousands of relevant articles from 13 local and national newspapers. Finally, from a list of 300 news facts, 11 news events about the index disaster were selected for the analysis based on their supposed impact. The events are listed in Table 1 in chronological order. In addition, six major and/or comparable disasters outside the Netherlands were selected (Table 2). The indexrelated subjects were front-page news at the time, at least in the region concerned. Because the question of who was to blame for the disaster was never answered, we concentrated on news reports (on the first day they were published) about suspect "de V" (news events 1, 8, and 11) and about the two directors (news events 5, 6, 7, and 11). From the international subjects the terrorist attacks in New York, Washington, and Madrid received an enormous amount of newspaper items and other media attention.

We analyzed the week from day 1 to 7 postattack. Because of the resemblance with the fireworks disaster we included the disasters in Toulouse, Belgium, and Denmark. Of these, the disaster in Toulouse did not get much attention (longer then 2 days) because it occurred 10 days after 9/11, whereas the disaster in Belgium occurred during the holiday months. The train explosion in Korea did receive only one item (on the front page).

\section{[TABLE 1]}

\section{[TABLE 2]}

These 17 events are shortly characterized in the following paragraphs.

First the local news events are described. In February 2001, 9 months after the disaster, a man was arrested who was suspected of having started the fire at the fireworks depot (named S.E. Fireworks) that led to the explosions (1). Later that month a governmental committee appointed to establish the causes of the disaster, published their report, known as the Oosting Report (2). This important report received a lot of media attention because it provided detailed information about the disaster, such as the number of firework containers on the factory property, and the illegality of the company's licence. Shortly after the disaster, questions were raised about how a licence could have been issued to store 158,250 kilograms of fireworks in a densely populated area. In addition, the ingredients of the fireworks material were unknown. As the local authorities were responsible for issuing and monitoring the factory's licence, the authorities were also subject to criminal investigation, but these charges were dropped in July 2001 (3). In September a book was published about the disaster (4). The criminal case against S.E. Fireworks started on March 5, 2002 (5) and ended one month later with the acquittal of the two managing directors (6). Two months after their acquittal one of the directors appeared in a television documentary (7). The arrested man who became known as "de V,” was found guilty in August 2002 and sentenced to 15 years in prison (8). In January 2003, the investigators were criticized for possible failures made in the accusation of de V (9). One month later, inflammation of leaking gas was assumed to have been the cause of the fire (10). 
Finally, on the same day 3 years after the disaster, the two managing directors of the fireworks factory were put in prison for one year, and on appeal "de V" was released from prison due to lack of evidence (11).

In addition to these local news events, we examined health changes related to six international disasters that received considerable attention in the Dutch media (Table 2). Four disasters were selected on the basis of their resemblance to the fireworks explosion.

This most obviously applied to the explosion of a fireworks factory in Kolding, Denmark (6), but also to an explosion at an artificial fertilizer factory in Toulouse, France (2), and to the explosion of a gas pipeline due to a leak, destroying two factories in an industrial park in Belgium (5). Fourth, in Korea, two train wagons carrying ammonium nitrate came into contact with a carriage containing fuel oil that resulted in a massive explosion in a railway station (4). Apart from these disasters we selected two terrorist attacks. First, the September 11, 2001, attacks in New York, in which the WTC was destroyed and the Pentagon in Washington was damaged (1). Three years later, Madrid suffered a terrorist attack, when 10 bombs exploded in four different commuter trains (3). The two terrorist attacks were adjusted for the great impact they had on mankind.

In the present study, we did not consider news events in the first 6 months after the disaster because we expected that the health complaints that victims presented in these months would directly be related to the disaster, and would override health complaints resulting from news events about the disaster.

\section{Design and Procedures}

Visits to general practitioners and health complaints presented to GPs before and after a selection of news events were compared for victims and for controls, who lived in the same city, but further away from the disaster scene and who had no personal damage.

Eleven local news events were selected directly related to the Enschede disaster (Table 1) as well as six about major international disasters (Table 2). For news events, we concentrated on local and national newspapers. Patient characteristics, utilization, and health complaints were collected from the electronic medical records of general practitioners in Enschede (Yzermans et al., 2005).

\section{DATA ANALYsis}

Data were used until 4 years after the disaster, excluding the 6-month period directly following the disaster. For each news event we recorded whether or not a patient had visited his GP (utilization) in the week before and/or after the news event, and the reason for this visit (health problem). We assumed that the impact of news could especially give rise to related health complaints in the first days after the event. More over, although we had to analyze using sometimes small figures, the alternative of using a longer period was less applicable because (a) we could not control for other events being of influence on the person's wellbeing, and (b) we aimed at comparable periods. However, the longer the period the more difficult it was to control this resemblance (holidays, Sundays, and public holidays).

A week always started on the first day after the news event.

In the case of the acquittal of the suspected "de V" on Tuesday, May 13, 2003, our period started the next day, on Wednesday, May 14, 2003. The period before the event always counted the same number of days as the period after. In this example, the week before the event started on May 6, and ended on May 12.

When the period after contained a Tuesday and a Wednesday, we compared this with a period before also containing a Tuesday and a Wednesday. When we were not able to compare the two periods because national holidays appeared in periods before or after, we chose the first normal business day that followed to replace the same day in the other week period.

Logistic regression analyses were carried out to compare utilization and health complaints before and after each news event. This was constructed per news event for the total group, as well as for victims and controls separately. As dependent variables we used whether or not patients had consulted their GP (utilization), and whether or not patients had presented health complaints to their GP (health outcome) in the relevant periods. The independent variable in each analysis indicated the week before (0) and after (1) a news event. Odds ratios with 95\% confidence intervals (CI) were used to detect differences in utilization and/or health complaints in the week after a news event compared to the week before. 


\section{[TABLE 3]}

\section{RESULTS}

Eleven local news events (Table 1) and six international news events (Table 2) were analyzed. After three local events a statistically significant increase in utilization was found when the week after the event was compared with the week before (Table 3). One event concerned the arrest of a man suspected of starting the fire that caused the explosions. The second event was the verdict of 15 years prison against the same man, and the third event concerned a theory of leaking gas pipelines that could have caused the disaster.

No significant increases in GP utilization were found after the other local news events. We consider the first of these events in more detail. In Figure 1 the utilization for this news-event is shown for victims and controls separately. On February 10, 2001, the man was arrested. In the figure the day of the arrest is marked with an arrow. Because this was on a Saturday, only few people visited their GP. Victims visited the GP a lot more than controls did, before and after the event. But it is the control group that showed a significant increase in utilization in the week after the news-event. A similar pattern of increased utilization of controls was found for the two other local news events (verdict suspect and the gas leak theory).

With regard to the international news events (Table 4), the only increases in GP utilization were seen in the week after terrorists attacked the WTC in New York and after the explosion in Belgium.

These increases, however, were not statistically significant. Also, in all other international events no significant increases in utilization were found in the week after the explosions. Furthermore, none of the local or international events showed a significant difference between victims and controls.

\section{[FIGUUR 1]}

For both victims and controls, we examined the type of health complaints they presented to their GP after index (Table 5) and international events (Table 6). Concerning the suspect of the disaster, the week after "de V" was arrested controls showed more problems with chronic diseases to their GP than the week before and the total group showed more symptoms of the skin. In the week after the verdict of "de V," MUPS, chronic diseases, and respiratory symptoms were the main reason for encounter for the total group. Medically unexplained physical symptoms, chronic diseases, and musculoskeletal symptoms emerged especially in the group of victims, whereas in the controls an increase in respiratory symptoms was visible. After the acquittal of "de V" no statistically significant differences were found, with the exception of less symptoms of the skin in the total group.

Concerning the two directors of the fireworks depot, there were more symptoms of the skin and of the musculoskeletal system presented to the GP after their case was started (total group and victims). After they were acquitted of charges no statistically significant changes occurred. Finally, after their imprisonment no increases were found.

\section{[TABLE 4]}

Victims and the total group presented more respiratory symptoms to their GP in the week after the news of the theory of leaking gas that may have caused the disaster. Controls showed an increase in MUPS this week. In victims and the total group more respiratory symptoms did arise after there were critical remarks about investigators. No statistically significant effects were seen for other news events (publishing of the Oosting Report about the causes of the disaster, of a book about the disaster, a TV documentary). As for the international news events, only after the New York disaster was an increase found for victims and the total group in MUPS.

Controls showed an increase in chronic diseases in this week. A significant decrease was found in all patients in presenting chronic diseases after the train explosion in North Korea and among victims and the total group after the terrorist attack in Madrid. After the gas explosion in Belgium more symptoms of the skin were seen in references. Finally, after the explosion in Kolding more MUPS were seen in controls.

\section{DISCUSSION}

In this study, utilization and health complaints of 2,854 victims of the Enschede fireworks disaster were compared with an equal number of controls for the possible influence of news events. Every patient in the Netherlands has his own GP who is familiar with his background and history, and who electronically 
registers his health complaints after each contact. By using these data our results were not influenced by recall bias, nor by subjective self-reporting.

We found a statistically significant increase in utilization in the week after 3 of the 11 local events concerning the index disaster.

Results showed an increase in utilization after the arrest and after the verdict of the suspect (“de V”), and after the news about leaking gas possibly causing the disaster. An increase in health complaints was also found after these three events. Changes not only occurred in the victims, but also in the controls. Between victims and controls no significant differences were found in increases of utilization and health complaints. From other studies we know that the personality trait of neuroticism also could be an important factor in the development of physical complaints and posttraumatic stress symptoms (Bramsen, Dirkzwager, \& van der Ploeg, 2000; Cox, MacPherson, Enns, \& McWilliams, 2004; Engelhard \& van den Hout, 2007). After the Enschede disaster, people could have been motivated by neuroticism in seeking media coverage and making health complaints. However, no data on patients' personality traits were available. We do know that news facts concerning "de V" brought about some disturbance to all residents of the city, victims as well as controls, and on the national level as well. In search of information about the one "who was to blame," controls, who were not directly involved in the disaster, were just as much concerned as the victims themselves. Otherwise, it is not clear why events concerning "de V" showed more impact than events concerning the directors of the depot, or the municipality who was to blame for the depot's license.

In his classification scheme, Taylor differentiated potential disaster victims into six groups (Taylor, 1987). The control group in our study could be classified in the group of the grieving people that was stunned by the event, or the group of people who shared the emotional burden of the postdisaster working situation with the victims. This phenomenon potentially appeared when, almost 3 years after the disaster, leaking gas pipelines were suggested as a possible cause of the disaster. After this news report, an increase in respiratory problems was found in the victims, and an increase of MUPS in the controls. The news may have worried people who lived in a less or uninvolved neighborhood. The gas could give a reason to visit a GP for reassurance that the escaped gas had not affected one's health. In 1999 something similar occurred, when 7 years after the plane crash in Amsterdam (the Bijlmermeer) it was rumored that the cargo of the plane contained toxic components.

It did not, but the media created a flow of news ("media hype”) on the basis of a "toxic agent cover-up," resulting in people reporting health complaints they attributed to the disaster (Vasterman et al., 2005; Yzermans et al., 2003; Yzermans \& Gersons, 2002).

\section{[TABLE 5]}

Results with regard to international events demonstrated that a few events seemed to affect people's health (as presented to their GP). Themost prominent increase in health complaints was found in the week after terrorists attacked the WTC. In contrast with the other selected international news events, dramatic images of airplanes crashing into the towers and the chaos on the scene were shown on television many times a day. Schuster and colleagues (2001) reported a significant correlation between the number of hours watching televised news coverage of the attacks and the percentage of adults experiencing increased stress responses. Also, the fact that these images resembled the fireworks disaster, with clouds of smoke and police sirens, may have affected the Enschede victims.

Victims showed more MUPS, and the controls more complaints of chronic diseases. No differences between victims and controls were found.

A remarkable outcome is the lack of increase in psychological problems presented to the GP in the week after any of the events.

\section{[TABLE 6]}

This is in contradiction to other studies where strong associations of television viewing of the $9 / 11$ attacks and posttraumatic stress disorder and depression were found. An explanation for this may be the way data were collected. First, as studies about disasters are usually based on self-report questionnaires that emphasize feelings between stress and depression, collected weeks after the disaster, we in contrast used data from GPs' registration systems which offers more objective information, collected immediately within the first week postevent. However, patients who visit their GP make an extra step, compared to people who 
experience symptoms, but do not consult their GP. Second, we studied a potential increase of psychological health complaints in the week after a news-event.

Complaints may have been presented already predisaster or postdisaster outside the timeframe we used, especially in the group of victims (but also in the controls) and for that reason an increase in psychological problems would be less noticed. Third, we looked at an immediate increase in psychological problems like feelings of fear, anxiety, or depression after the news event; other studies focussed on a longer period during which these problems may have had time to accumulate. Signals from the initial phase of these problems can be physical, and interpreted as "in general not feeling well." We found increases in some of these MUPS such as tiredness, headache, nausea, and abdominal pain. It underlines the importance for GPs to pay attention to MUPS and the possible association with news events.

Some methodological issues need to be considered. There is a dependency on theGPs' database. Patients who experienced health complaints, but who did not visit the GP did not participate in the study. So results are based on a selection: victims and controls who did visit the GP. This results in an underestimation of the actual number of symptoms experienced. Also, we tried to quantify exposure to news coverage.Herewe had to deal with small numbers of visits in the one-week periods being compared. For instance, the significant increase in the victims group in MUPS the week after "Verdict suspect" is based on 58 patients in the week before- and 81 in the week after the news event. And the increase in MUPS within the total group (N $=5708$ ) counts 109 patients in the week before and 143 in the week after. Furthermore, we assumed that when people do react on a news-event by visiting their GP, they will do so pretty fast. A one-week period might be too short and we had to deal with rather small numbers, with an increased chance for instability in the estimates. Nevertheless, we did find increases in health complaints after a number of news events.

In conclusion, in this study we found increased utilization and health complaints after some news events, but less than expected compared to studies in the United States based on self-report.

Data was used from GPs' registration systems, which offers relative objective information. Finally, we wonder why the influence of news events was smaller than we expected. Apart from using no self-report but more objective data and limiting the study to a period of one week, we conclude that the influence of news events on the short-term health complaints as presented to the GP are probably overestimated. Because we used controls from the same city and general practices, it is possible that differences between victims and controls are smaller thanwith controls fromother parts of the country. However, in analyses of other studies on the same disaster it was concluded that these controls resembled more the average Dutch population in figures for morbidity and utilization in the postdisaster period than the victims.

Based on our results, we do not advocate the relocation of health resources on the basis of news reports if such reports show an increase of utilization or symptoms presented to the GP. On the other hand, we underline an important lesson for any caregiver that,when increases in utilization and symptoms presented are seen after news reports, it always concerns physical symptoms and not psychological problems. More studies that explicitly examine the role of the media (news events) in the aftermath of disaster are encouraged (Vasterman et al., 2005).

\section{REFERENCES}

Ahern, J., Galea, S., Resnick, H., \& Vlahov, D. (2004). Television images and probable posttraumatic stress disorder after September 11: The role of background characteristics, event exposure, and perievent panic. Journal ofNervous and Mental Disease, 192, 217-226.

Ahern, J., Galea, S., Resnick, H., Kilpatrick, D., Bucuvalas, M., Gold, J., et al.

(2002). Television images and psychological symptoms after the September 11 terrorist attacks. Psychiatry, 65, 289-300.

American Psychiatric Association. (1994). Diagnostic and statistical manual of mental disorders (4th ed.). Washington, DC: Author.

Bramsen, I., Dirkzwager, A. J. E., \& van der Ploeg, H. M. (2000). Predeployment personality traits and exposure to trauma as predictors of posttraumatic stress symptoms: A prospective study of former peacekeepers. American Journal of Psychiatry, 157, 1115-1119.

Bromet, E. J., \& Havenaar, J. M. (2002). Mental health consequences of disasters.

In N. Sartorius, W. Gaebel, J. J. Lopez-Ibor, \& M. Maj (Eds.), Psychiatry in society (pp. 241-260).

Chicester, UK: Wiley.

Cohen-Silver, R., Holman, E. A., McIntosh, D. N., Poulin, M., \& Gil-Rivas, V.

(2002).Nationwide longitudinal study of psychological responses to September 11. Journal of the American Medical Association, 288, 1235-1244. 
Veen, P.M.H. ten, Morren, M., IJzermans, C.J. The influence of news-events on health after disaster: longitudinal study in general practice. Journal of Traumatic Stress: 2009, 22(6), 505-515

Cox, B. J., MacPherson, P. S. R., Enns, M. W., \& McWilliams, L. A. (2004).

Neuroticism and self-criticism associated with posttraumatic stress disorder in a nationally representative sample. Behaviour Research and Therapy, 42, 105-114.

Donker, G. A., Yzermans, C. J., Spreeuwenberg, P., \& van der Zee, J. (2002).

Symptom attribution after a plane crash: Comparison between self-reported symptoms and GP records.

British Journal of General Practice, 52, 917-922.

Engelhard, I. M., \& van den Hout, M. A. (2007). Preexisting neuroticism, subjective stressor severity, and posttraumatic stress in soldiers deployed to Iraq.

Canadian Journal of Psychiatry, 52, 505-509.

Escobar, J. L., Canino, G., Rubio-Stiper, M., \& Bravo, M. (1992). Somatic symptoms after a natural disaster: A prospective study. American Journal of Psychiatry, 149, 965-967.

Gortner, E. M., \& Pennebaker, J. W. (2003). The archival anatomy of a disaster: Media coverage and community-wide health effects of the Texas A\&Mbonfire tragedy. Journal of Social and Clinical Psychology, 22, 580-603.

Lamberts, H., \& Wood, M. (1987). International Classification of Primary Care.

Oxford, UK: Oxford University Press.

Norris, F. H., Friedman, M. J., Watson, P. J., Byrne, C. M., Diaz, E., \& Kaniasty, K. (2002). 60,000 Disaster victims speak: Part I: An empirical review of the empirical literature, 1981-2001. Psychiatry, 65, $207-239$.

Rubonis, A. V., \& Bickman, L. (1991). Psychological impairment in the wake of disaster: The disasterpsychopathology relationship. Psychological Bulletin, 109, 384-399.

Schlenger, W. E., Caddell, J. M., Ebert, L., Jordan, B. K., Rourke, K. M., Wilson, D., et al. (2002).

Psychological reactions to terrorist attacks: Findings from the national study of Americans' reactions to September 11. Journal of the American Medical Association, 288, 581-588.

Schnurr, P. P., Spiro, A.,\&Paris, A.H. (2000). Physician-diagnosed media medical disorders in relation to PTSD symptoms in older military veterans. Health Psychology, 19, 91-97.

Schuster,M. A., Stein, B. D., Jaycox, L. H., Collins, R. L.,Marshall, G. N., Elliott, M. N., et al. (2001). A national survey of stress reactions after the September 11, 2001 terrorist attacks. New England Journal of Medicine, 345, 1507- 1512.

Taylor, A. J. W. (1987). A taxonomy of disasters and their victims. Journal of Psychosomatic Research, 31, 535-541.

Vasterman, P., Yzermans, C. J., \& Dirkzwager, A. J. E. (2005). The role of the media and media hypes in the aftermath of disasters. Epidemiologic Reviews, 27, 107-114.

World Health Organization. (1992). International Classification of Diseases.

Geneva: Author.

Yzermans, C. J., \& Gersons, B. P. R. (2002). The chaotic aftermath of an airplane crash in Amsterdam: A second disaster. In J. M. Havenaar, J. G. Cwikel, \& E. J. Bromet (Eds.), Toxic turmoil: Psychological and societal consequences of ecological disaster (pp. 85-99). New York: Kluwer Academic.

Yzermans, C. J., Donker, G. A., \& Vasterman, P. (2003). The impact of disasters: Long term effects on health. In W. Kirch (Ed.), Public Health in Europe: 10 years EUPHA (pp. 317-341). Berlin: Springer.

Yzermans, C. J., Donker, G. A., Kerssens, J. J., Dirkzwager, A. J. E., Soeteman, J. H., \& ten Veen, P. M. H. (2005). Health problems of victims before and after a disaster: A longitudinal study in general practice. International Journal of Epidemiology, 34, 820-826. 
Veen, P.M.H. ten, Morren, M., IJzermans, C.J. The influence of news-events on health after disaster: a 7 longitudinal study in general practice. Journal of Traumatic Stress: 2009, 22(6), 505-515

\section{TABLES AND FIGURES}

Table 1. News Events Related to the Fireworks Disaster

\begin{tabular}{rllc}
\hline & \multicolumn{1}{c}{ Event } & \multicolumn{1}{c}{ Short issue } & Date \\
\hline 1 & Suspect "de V" arrested & "Suspect arrested" & $2 / 10 / 2001$ \\
2 & $\begin{array}{l}\text { Presentation of the Oosting Report, a detailed report } \\
\text { of the investigation that was done after the disaster }\end{array}$ & "Oosting Report" & $2 / 28 / 2001$ \\
3 & Municipality acquitted from charge & "Municipality acquitted" & $7 / 18 / 2001$ \\
4 & Book published about the disaster & "Book published" & $9 / 28 / 2001$ \\
5 & Start criminal case against fireworks depot directors & "Case against Fireworks depot" & $3 / 5 / 2002$ \\
6 & Acquittal of the two managing directors & "Acquittal directors" & $4 / 3 / 2002$ \\
7 & TV documentary in which one of the fireworks depot's directors appeared & "TV doc." & $5 / 24 / 2002$ \\
8 & Verdict of 15 years prison against "de V" & "Verdict suspect" & $8 / 9 / 2002$ \\
9 & Critical remarks pointed at investigators & "Critical remarks" & $1 / 25 / 2003$ \\
10 & Theory of leaking gas pipelines that caused the disaster & "Gas leak theory" & $2 / 27 / 2003$ \\
11 & Acquittal of the accused suspected man "de V" and & $5 / 13 / 2003$ \\
& two managing directors of the fireworks factory put in prison for one year & "Acquittal suspect" & $5 / 13 / 2003$ \\
\hline
\end{tabular}

Note. The disaster date was May 13, 2000.

Table 2. News Events Related to International Disasters

\begin{tabular}{ccc}
\hline Disaster & Description & Date \\
\hline
\end{tabular}

1 Terrorist attacks, New York and Washington

2 Explosion, Toulouse, France

3 Terrorist attack, Madrid, Spain

$4 \quad$ Train explosion, North Korea

5 Explosion, Wallonia, Belgium

6 Explosion, Kolding, Denmark
Terrorists hijacked four commercial airliners. Two of the airliners were crashed into the World Trade Center in New York City resulting in the collapse of both buildings soon afterward: 2,974 people died and 24 people missing. The third airliner was crashed into the Pentagon near Washington, DC. On the fourth aircraft, passengers and the crew attempted to retake control of the plane from the hijackers.

In an industrial zone on the outskirts of Toulouse, southwestern France, a huge explosion ripped through AZF (AZote Fertilisant) fertilizer factory: 31 people were reported dead. The total number of injuries was 3,500 .

Madrid suffered a terrorist attack when 10 bombs exploded in four different trains in downtown Madrid. The total number of deaths was 192 ; nearly 1,500 persons were injured.

An explosion occurred in the railway station of Ryonchong, in the northwest of Korea. The explosion in the city with 130,000 inhabitants destroyed 1,850 houses and damaged another 6,300 . There were 161 death and 1,300 injured.

A gas explosion in an industrial zone southwest of Brussels killed 24 people and 132 were wounded.

In Kolding, Denmark, a fireworks factory exploded; 350 houses were rendered uninhabitable. One firefighter died and 84 people were injured.

$9 / 11 / 2001$

$9 / 21 / 2001$

$3 / 11 / 2004$

$4 / 22 / 2004$

$7 / 30 / 2004$

$11 / 3 / 2004$

Table 3. Effects of Local News Events on Healthcare Utilization in the Total Sample, Victims and Controls

\begin{tabular}{|c|c|c|c|c|c|c|}
\hline \multirow[b]{2}{*}{ News event } & \multicolumn{2}{|c|}{ Total group } & \multicolumn{2}{|c|}{ Victims } & \multicolumn{2}{|c|}{ Controls } \\
\hline & OR & $95 \% \mathrm{CI}$ & OR & $95 \% \mathrm{CI}$ & OR & $95 \% \mathrm{CI}$ \\
\hline Suspect arrested & 1.15 & $1.02-1.31^{*}$ & 1.04 & $0.88-1.24$ & 1.32 & $1.10-1.60^{*}$ \\
\hline Oosting Report & 0.99 & $0.87-1.11$ & 0.93 & $0.79-1.10$ & 1.06 & $0.88-1.26$ \\
\hline Municipality acquitted & 0.88 & $0.77-1.02$ & 0.87 & $0.71-1.06$ & 0.90 & $0.73-1.12$ \\
\hline Book published & 0.99 & $0.88-1.13$ & 0.95 & $0.80-1.12$ & 1.06 & $0.88-1.27$ \\
\hline Case against Fireworks depot & 1.07 & $0.95-1.20$ & 1.09 & $0.93-1.28$ & 1.04 & $0.87-1.24$ \\
\hline Acquittal directors & 1.05 & $0.92-1.19$ & 0.99 & $0.83-1.19$ & 1.10 & $0.92-1.34$ \\
\hline TV documentary & 1.01 & $0.90-1.14$ & 1.09 & $0.93-1.27$ & 0.93 & $0.78-1.11$ \\
\hline Verdict suspect & 1.21 & $1.07-1.38^{* *}$ & 1.17 & $0.99-1.40$ & 1.25 & $1.04-1.51^{*}$ \\
\hline Critical remarks & 1.06 & $0.94-1.20$ & 1.09 & $0.93-1.27$ & 1.03 & $0.86-1.23$ \\
\hline Gas leak theory & 1.25 & $1.11-1.41^{* * *}$ & 1.19 & $1.01-1.40^{*}$ & 1.32 & $1.11-1.58^{*}$ \\
\hline Acquittal suspect/Imprisonment directors & 0.94 & $0.84-1.05$ & 0.92 & $0.79-1.08$ & 0.95 & $0.81-1.12$ \\
\hline
\end{tabular}

${ }^{*} p<.05 .{ }^{* *} p<.01 .{ }^{* *} p<.001$, two-tailed. 


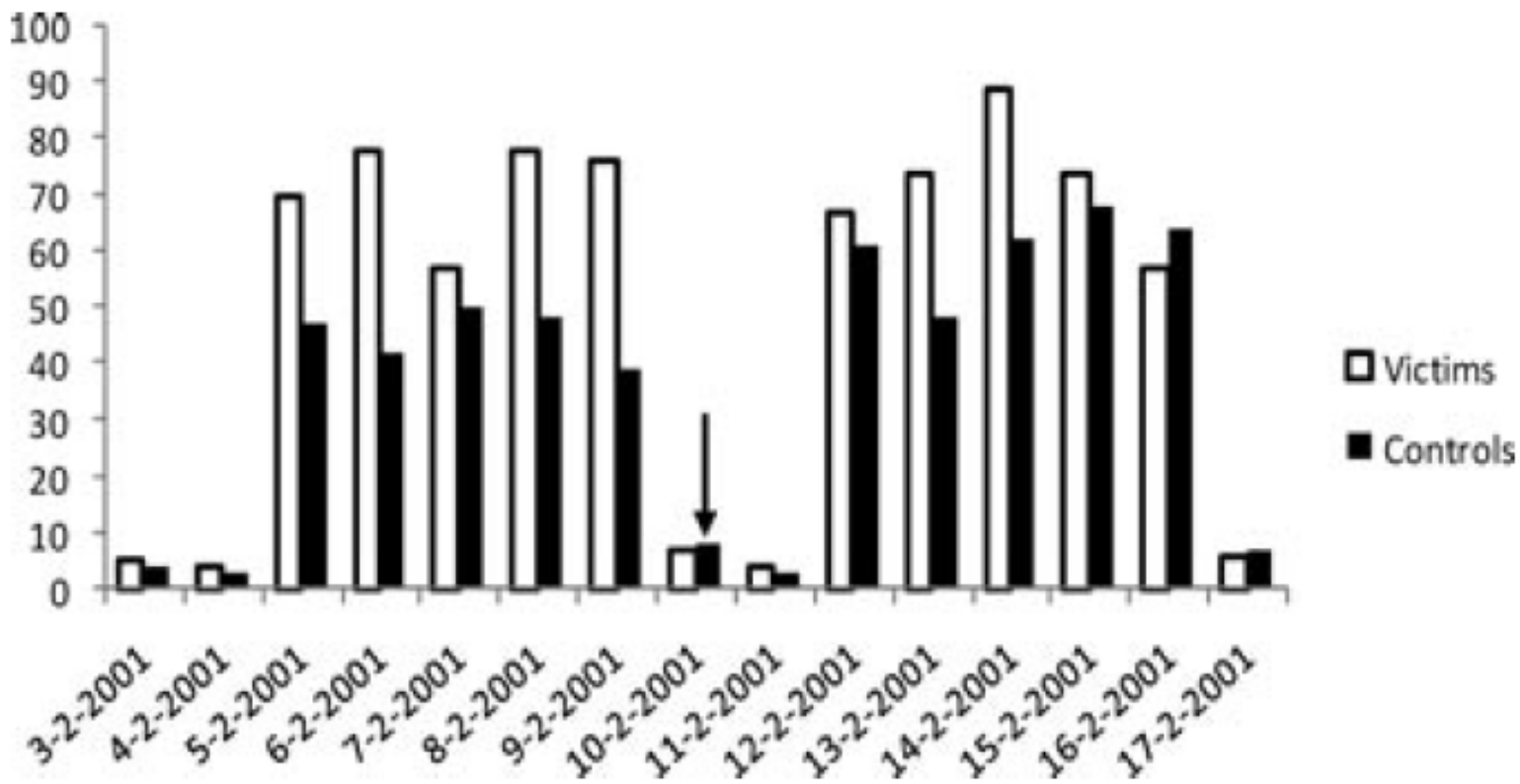

Figure 1. Utilization of victims and controls before and after suspect "de V" was arrested for setting the fireworks depot on fire.

Table 4. Effects of International News Events on Healthcare Utilization in the Total Sample, Victims, and Controls

\begin{tabular}{|c|c|c|c|c|c|c|}
\hline \multirow[b]{2}{*}{ News event } & \multicolumn{2}{|c|}{ Total group } & \multicolumn{2}{|c|}{ Victims } & \multicolumn{2}{|c|}{ Controls } \\
\hline & OR & $95 \% \mathrm{CI}$ & OR & $95 \% \mathrm{CI}$ & OR & $95 \% \mathrm{CI}$ \\
\hline Terrorist attacks, New York and Washington & 1.14 & $0.99-1.29$ & 1.18 & $0.99-1.40$ & 1.08 & $0.89-1.32$ \\
\hline Explosion, Toulouse, France & 0.94 & $0.82-1.07$ & 0.91 & $0.76-1.08$ & 0.99 & $0.80-1.19$ \\
\hline Terrorist attack, Madrid, Spain & 0.88 & $0.78-0.99^{*}$ & 0.85 & $0.72-1.01$ & 0.91 & $0.76-1.08$ \\
\hline Train explosion, North Korea & 0.96 & $0.85-1.08$ & 0.94 & $0.80-1.11$ & 0.97 & $0.82-1.15$ \\
\hline Explosion, Wallonia, Belgium & 1.09 & $0.93-1.26$ & 1.07 & $0.87-1.31$ & 1.11 & $0.89-1.39$ \\
\hline Explosion, Kolding, Denmark & 0.98 & $0.87-1.11$ & 0.97 & $0.82-1.15$ & 0.99 & $0.83-1.18$ \\
\hline
\end{tabular}

${ }^{*} p<.05 .{ }^{* *} p<.01 .{ }^{* * *} p<.001$, two-tailed. 
Veen, P.M.H. ten, Morren, M., IJzermans, C.J. The influence of news-events on health after disaster: longitudinal study in general practice. Journal of Traumatic Stress: 2009, 22(6), 505-515

Table 5. Effects of Items in Dutch Newspapers on Health Complaints in the Total Sample, Victims, and Controls

\begin{tabular}{|c|c|c|c|c|c|c|}
\hline \multirow[b]{2}{*}{ News event } & \multicolumn{2}{|c|}{ Total group } & \multicolumn{2}{|c|}{ Victims } & \multicolumn{2}{|c|}{ Controls } \\
\hline & OR & $95 \% \mathrm{CI}$ & OR & $95 \% \mathrm{CI}$ & OR & $95 \% \mathrm{CI}$ \\
\hline \multicolumn{7}{|c|}{ Suspect arrested } \\
\hline MUPS & 1.24 & $0.97-1.58$ & 1.26 & $0.92-1.72$ & 1.21 & $0.82-1.78$ \\
\hline Chronic & 1.17 & $0.93-1.49$ & 0.91 & $0.66-1.26$ & 1.56 & $1.10-2.22^{* *}$ \\
\hline Psychological & 1.24 & $0.93-1.66$ & 1.25 & $0.89-1.76$ & 1.22 & $0.70-2.12$ \\
\hline Respiratory & 1.40 & $0.84-2.35$ & 1.59 & $0.77-3.28$ & 1.23 & $0.59-2.57$ \\
\hline Skin & 2.00 & $1.06-3.81^{*}$ & 2.61 & $0.93-7.33$ & 1.67 & $0.73-3.82$ \\
\hline Locomotor & 1.17 & $0.79-1.71$ & 1.45 & $0.87-2.41$ & 0.87 & $0.49-1.57$ \\
\hline \multicolumn{7}{|c|}{ Oosting Report } \\
\hline MUPS & 1.17 & $0.93-1.47$ & 1.12 & $0.82-1.53$ & 1.23 & $0.87-1.74$ \\
\hline Chronic & 1.07 & $0.85-1.34$ & 1.00 & $0.73-1.38$ & 1.14 & $0.82-1.59$ \\
\hline Psychological & 0.91 & $0.68-1.23$ & 0.98 & $0.68-1.41$ & 0.77 & $0.45-1.32$ \\
\hline Respiratory & 1.06 & $0.66-1.73$ & 1.00 & $0.50-2.00$ & 1.13 & $0.57-2.21$ \\
\hline Skin & 1.00 & $0.60-1.66$ & 1.00 & $0.51-1.96$ & 1.00 & $0.46-2.16$ \\
\hline Locomotor & 1.13 & $0.78-1.64$ & 0.94 & $0.56-1.56$ & 1.40 & $0.82-2.39$ \\
\hline \multicolumn{7}{|c|}{ Municipality acquitted } \\
\hline MUPS & 1.04 & $0.76-1.41$ & 1.02 & $0.67-1.56$ & 1.06 & $0.67-1.66$ \\
\hline Chronic & 1.03 & $0.78-1.37$ & 0.92 & $0.62-1.37$ & 1.16 & $0.77-1.75$ \\
\hline Psychological & 0.73 & $0.48-1.11$ & 0.77 & $0.46-1.08$ & 0.65 & $0.30-1.38$ \\
\hline Respiratory & 1.00 & $0.48-2.10$ & 1.17 & $0.39-3.48$ & 0.88 & $0.32-2.42$ \\
\hline Skin & 0.81 & $0.46-1.43$ & 0.93 & $0.44-1.98$ & 0.69 & $0.30-1.62$ \\
\hline Locomotor & 0.90 & $0.53-1.52$ & 0.95 & $0.50-1.81$ & 0.82 & $0.34-1.98$ \\
\hline \multicolumn{7}{|c|}{ Book published } \\
\hline MUPS & 0.89 & $0.70-1.13$ & 0.88 & $0.63-1.22$ & 0.89 & $0.63-1.27$ \\
\hline Chronic & 0.99 & $0.78-1.24$ & 0.96 & $0.69-1.33$ & 1.01 & $0.73-1.40$ \\
\hline Psychological & 1.06 & $0.76-1.48$ & 0.78 & $0.53-1.17$ & 2.25 & $1.17-4.33^{*}$ \\
\hline Respiratory & 1.57 & $0.93-2.65$ & 1.50 & $0.72-3.13$ & 1.64 & $0.77-3.48$ \\
\hline Skin & 0.93 & $0.55-1.57$ & 0.65 & $0.32-1.31$ & 1.56 & $0.67-3.61$ \\
\hline Locomotor & 0.75 & $0.51-1.12$ & 0.96 & $0.56-1.64$ & 0.55 & $0.30-1.01$ \\
\hline \multicolumn{7}{|c|}{ Case against fireworks depot } \\
\hline MUPS & 1.05 & $0.84-1.31$ & 1.24 & $0.92-1.66$ & 0.85 & $0.60-1.19$ \\
\hline Chronic & 1.06 & $0.85-1.31$ & 1.15 & $0.84-1.57$ & 0.98 & $0.73-1.32$ \\
\hline Psychological & 0.85 & $0.62-1.17$ & 0.86 & $0.57-1.29$ & 0.84 & $0.50-1.41$ \\
\hline Respiratory & 0.91 & $0.59-1.40$ & 1.00 & $0.57-1.77$ & 0.79 & $0.40-1.56$ \\
\hline Skin & 2.26 & $1.33-3.83^{* *}$ & 3.69 & $1.49-9.11^{* *}$ & 1.65 & $0.85-3.21$ \\
\hline Locomotor & 1.45 & $1.02-2.07^{*}$ & 1.72 & $1.06-2.77^{*}$ & 1.16 & $0.68-1.99$ \\
\hline \multicolumn{7}{|c|}{ Acquittal directors } \\
\hline MUPS & 0.92 & $0.71-1.20$ & 0.80 & $0.56-1.14$ & 1.10 & $0.75-1.63$ \\
\hline Chronic & 1.15 & $0.91-1.46$ & 0.99 & $0.71-1.36$ & 1.37 & $0.96-1.94$ \\
\hline Psychological & 0.98 & $0.68-1.42$ & 0.97 & $0.61-1.55$ & 1.00 & $0.54-1.86$ \\
\hline Respiratory & 1.30 & $0.81-2.10$ & 1.27 & $0.58-2.81$ & 1.32 & $0.73-2.40$ \\
\hline Skin & 0.67 & $0.41-1.10$ & 0.60 & $0.29-1.23$ & 0.75 & $0.38-1.47$ \\
\hline Locomotor & 0.80 & $0.52-1.24$ & 0.85 & $0.49-1.49$ & 0.74 & $0.37-1.47$ \\
\hline
\end{tabular}


Veen, P.M.H. ten, Morren, M., IJzermans, C.J. The influence of news-events on health after disaster: longitudinal study in general practice. Journal of Traumatic Stress: 2009, 22(6), 505-515

Table 5. (Continued)

\begin{tabular}{|c|c|c|c|c|c|c|}
\hline \multirow[b]{2}{*}{ News event } & \multicolumn{2}{|c|}{ Total group } & \multicolumn{2}{|c|}{ Victims } & \multicolumn{2}{|c|}{ Controls } \\
\hline & OR & $95 \% \mathrm{CI}$ & OR & $95 \% \mathrm{CI}$ & OR & $95 \% \mathrm{CI}$ \\
\hline \multicolumn{7}{|c|}{ TV documentary } \\
\hline MUPS & 1.06 & $0.85-1.32$ & 1.00 & $0.75-1.34$ & 1.14 & $0.82-1.59$ \\
\hline Chronic & 1.03 & $0.84-1.27$ & 1.07 & $0.80-1.42$ & 0.99 & $0.73-1.35$ \\
\hline Psychological & 0.73 & $0.54-1.00$ & 0.72 & $0.49-1.04$ & 0.78 & $0.44-1.38$ \\
\hline Respiratory & 0.69 & $0.40-1.18$ & 0.69 & $0.32-1.48$ & 0.65 & $0.30-1.38$ \\
\hline Skin & 0.85 & $0.53-1.35$ & 0.71 & $0.34-1.48$ & 0.95 & $0.52-1.74$ \\
\hline Locomotor & 1.21 & $0.86-1.70$ & 1.28 & $0.81-2.02$ & 1.14 & $0.67-1.86$ \\
\hline \multicolumn{7}{|l|}{ Verdict suspect } \\
\hline MUPS & 1.32 & $1.03-1.70^{*}$ & 1.41 & $1.00-1.98^{*}$ & 1.22 & $0.84-1.78$ \\
\hline Chronic & 1.26 & $1.01-1.58^{*}$ & 1.44 & $1.04-1.99^{*}$ & 1.12 & $0.82-1.53$ \\
\hline Psychological & 1.21 & $0.88-1.67$ & 1.21 & $0.79-1.86$ & 1.21 & $0.74-1.99$ \\
\hline Respiratory & 2.08 & $1.07-4.04^{*}$ & 1.46 & $0.68-3.15$ & 5.52 & $1.22-24.93^{*}$ \\
\hline Skin & 1.00 & $0.65-1.53$ & 0.65 & $0.34-1.25$ & 1.40 & $0.79-2.50$ \\
\hline Locomotor & 1.33 & $0.91-1.95$ & 1.77 & $1.04-3.04^{*}$ & 0.96 & $0.55-1.69$ \\
\hline \multicolumn{7}{|c|}{ Critical remarks } \\
\hline MUPS & 1.06 & $0.85-1.32$ & 1.05 & $0.78-1.42$ & 1.07 & $0.77-1.50$ \\
\hline Chronic & 0.98 & $0.79-1.22$ & 1.19 & $0.88-1.61$ & 0.80 & $0.58-1.09$ \\
\hline Psychological & 1.20 & $0.89-1.61$ & 1.42 & $0.97-2.09$ & 0.92 & $0.57-1.47$ \\
\hline Respiratory & 1.82 & $1.14-2.92^{*}$ & 2.25 & $1.16-4.33^{*}$ & 1.43 & $0.72-2.84$ \\
\hline Skin & 0.87 & $0.52-1.46$ & 1.34 & $0.63-2.83$ & 0.58 & $0.27-1.22$ \\
\hline Locomotor & 1.16 & $0.81-1.66$ & 1.37 & $0.85-2.20$ & 0.93 & $0.54-1.60$ \\
\hline \multicolumn{7}{|l|}{ Gas leak theory } \\
\hline MUPS & 1.44 & $1.14-1.80^{* *}$ & 1.35 & $0.99-1.84$ & 1.55 & $1.11-2.16^{*}$ \\
\hline Chronic & 1.11 & $0.90-1.37$ & 1.11 & $0.84-1.47$ & 1.12 & $0.82-1.53$ \\
\hline Psychological & 1.04 & $0.76-1.42$ & 0.98 & $0.66-1.45$ & 1.16 & $0.68-1.96$ \\
\hline Respiratory & 2.27 & $1.44-3.58^{* * *}$ & 3.31 & $1.68-6.51^{* *}$ & 1.57 & $0.84-2.94$ \\
\hline Skin & 1.35 & $0.87-2.09$ & 1.39 & $0.76-2.56$ & 1.30 & $0.69-2.45$ \\
\hline Locomotor & 1.23 & $0.85-1.76$ & 0.93 & $0.55-1.58$ & 1.57 & $0.95-2.60$ \\
\hline \multicolumn{7}{|c|}{ Acquittal suspect/Imprisonment directors } \\
\hline MUPS & 0.89 & $0.71-1.11$ & 0.87 & $0.63-1.19$ & 0.91 & $0.66-1.25$ \\
\hline Chronic & 1.03 & $0.85-1.26$ & 1.04 & $0.79-1.37$ & 1.02 & $0.77-1.35$ \\
\hline Psychological & 1.07 & $0.80-1.43$ & 1.23 & $0.85-1.77$ & 0.83 & $0.51-1.35$ \\
\hline Respiratory & 1.31 & $0.79-2.19$ & 1.27 & $0.58-2.81$ & 1.34 & $0.68-2.62$ \\
\hline Skin & 0.64 & $0.41-0.99^{*}$ & 0.69 & $0.37-1.32$ & 0.59 & $0.32-1.10$ \\
\hline Locomotor & 1.08 & $0.74-1.57$ & 1.15 & $0.68-2.02$ & 1.00 & $0.60-1.68$ \\
\hline
\end{tabular}

Note. MUPS = Medical unexplained physical symptoms; Chronic $=$ chronic diseases; Psychological $=$ psychological problems and disorders; Locomotor $=$ musculoskeletal symptoms and diseases.

${ }^{*} p<.05 .^{* *} p<.01 .^{* * *} p<.001$, two-tailed. 
Veen, P.M.H. ten, Morren, M., IJzermans, C.J. The influence of news-events on health after disaster: longitudinal study in general practice. Journal of Traumatic Stress: 2009, 22(6), 505-515

Table 6. Effects of International News Items on Health Complaints in the Total Sample, Victims, and Controls

\begin{tabular}{|c|c|c|c|c|c|c|}
\hline \multirow[b]{2}{*}{ News event } & \multicolumn{2}{|c|}{ Total group } & \multicolumn{2}{|c|}{ Victims } & \multicolumn{2}{|c|}{ Controls } \\
\hline & OR & $95 \% \mathrm{CI}$ & OR & $95 \% \mathrm{CI}$ & OR & $95 \% \mathrm{CI}$ \\
\hline \multicolumn{7}{|c|}{ Terrorist attacks, New York and Washington } \\
\hline MUPS & 1.41 & $1.10-1.81^{* *}$ & 1.44 & $1.05-1.99^{*}$ & 1.36 & $0.92-2.01$ \\
\hline Chronic & 1.38 & $1.08-1.77^{* *}$ & 1.21 & $0.86-1.70$ & 1.61 & $1.12-2.33^{* *}$ \\
\hline Psychological & 1.12 & $0.82-1.54$ & 1.43 & $0.96-2.12$ & 0.72 & $0.42-1.23$ \\
\hline Respiratory & 1.18 & $0.67-2.09$ & 1.27 & $0.58-2.81$ & 1.09 & $0.48-2.48$ \\
\hline Skin & 0.85 & $0.49-1.49$ & 0.78 & $0.36-1.73$ & 0.92 & $0.40-2.08$ \\
\hline Locomotor & 1.36 & $0.93-1.98$ & 1.33 & $0.81-2.17$ & 1.40 & $0.79-2.50$ \\
\hline \multicolumn{7}{|c|}{ Explosion, Toulouse, France } \\
\hline MUPS & 0.88 & $0.69-1.12$ & 0.84 & $0.61-1.17$ & 0.92 & $0.64-1.32$ \\
\hline Chronic & 0.92 & $0.73-1.17$ & 0.81 & $0.59-1.13$ & 1.07 & $0.75-1.51$ \\
\hline Psychological & 0.76 & $0.54-1.07$ & 0.86 & $0.58-1.26$ & 0.52 & $0.25-1.09$ \\
\hline Respiratory & 0.80 & $0.44-1.44$ & 0.92 & $0.40-2.08$ & 0.69 & $0.30-1.62$ \\
\hline Skin & 0.88 & $0.50-1.55$ & 1.46 & $0.68-3.15$ & 0.47 & $0.19-1.14$ \\
\hline Locomotor & 0.78 & $0.53-1.15$ & 0.73 & $0.42-1.27$ & 0.83 & $0.48-1.42$ \\
\hline \multicolumn{7}{|c|}{ Terrorist attack, Madrid, Spain } \\
\hline MUPS & 0.93 & $0.72-1.21$ & 1.07 & $0.75-1.54$ & 0.81 & $0.57-1.17$ \\
\hline Chronic & 0.74 & $0.59-0.94^{*}$ & 0.59 & $0.42-0.83^{* *}$ & 0.92 & $0.66-1.28$ \\
\hline Psychological & 0.93 & $0.61-1.42$ & 0.63 & $0.32-1.24$ & 1.22 & $0.70-2.12$ \\
\hline Respiratory & 1.19 & $0.74-1.91$ & 0.94 & $0.47-1.87$ & 1.47 & $0.76-2.84$ \\
\hline Skin & 0.71 & $0.42-1.19$ & 0.65 & $0.32-1.31$ & 0.78 & $0.36-1.73$ \\
\hline Locomotor & 1.18 & $0.74-1.86$ & 1.40 & $0.72-2.73$ & 1.00 & $0.53-1.89$ \\
\hline \multicolumn{7}{|c|}{ Train explosion, North Korea } \\
\hline MUPS & 0.96 & $0.76-1.21$ & 1.05 & $0.77-1.45$ & 0.85 & $0.59-1.21$ \\
\hline Chronic & 0.73 & $0.59-0.89^{* *}$ & 0.74 & $0.56-0.98^{*}$ & 0.71 & $0.53-0.96^{*}$ \\
\hline Psychological & 1.11 & $0.77-1.59$ & 1.15 & $0.72-1.85$ & 1.04 & $0.59-1.83$ \\
\hline Respiratory & 1.03 & $0.64-1.65$ & 1.45 & $0.79-2.65$ & 0.56 & $0.25-1.27$ \\
\hline Skin & 1.31 & $0.76-2.25$ & 1.22 & $0.60-2.47$ & 1.45 & $0.62-3.39$ \\
\hline Locomotor & 1.10 & $0.75-1.62$ & 1.16 & $0.68-1.96$ & 1.04 & $0.59-1.83$ \\
\hline \multicolumn{7}{|c|}{ Explosion, Wallonia, Belgium } \\
\hline MUPS & 0.85 & $0.62-1.17$ & 0.93 & $0.62-1.42$ & 0.73 & $0.44-1.23$ \\
\hline Chronic & 0.96 & $0.73-1.26$ & 1.04 & $0.72-1.50$ & 0.89 & $0.60-1.32$ \\
\hline Psychological & 1.39 & $0.84-2.30$ & 1.36 & $0.72-2.54$ & 1.45 & $0.62-3.39$ \\
\hline Respiratory & 0.62 & $0.33-1.19$ & 0.58 & $0.27-1.22$ & 0.80 & $0.22-2.98$ \\
\hline Skin & 1.58 & $0.89-2.81$ & 1.08 & $0.51-2.30$ & 2.68 & $1.05-6.85^{*}$ \\
\hline Locomotor & 1.27 & $0.76-2.13$ & 1.43 & $0.72-2.84$ & 1.08 & $0.49-2.38$ \\
\hline \multicolumn{7}{|c|}{ Explosion, Kolding, Denmark } \\
\hline MUPS & 1.18 & $0.92-1.52$ & 0.91 & $0.65-1.28$ & 1.61 & $1.10-2.35^{*}$ \\
\hline Chronic & 1.06 & $0.84-1.35$ & 0.84 & $0.60-1.16$ & 1.39 & $0.98-1.98$ \\
\hline Psychological & 1.32 & $0.93-1.86$ & 1.23 & $0.79-1.91$ & 1.46 & $0.85-2.52$ \\
\hline Respiratory & 1.11 & $0.66-1.85$ & 1.78 & $0.79-4.04$ & 0.79 & $0.40-1.56$ \\
\hline Skin & 1.35 & $0.81-2.24$ & 1.20 & $0.60-2.39$ & 1.55 & $0.72-3.31$ \\
\hline Locomotor & 1.07 & $0.71-1.61$ & 0.93 & $0.54-1.60$ & 1.28 & $0.69-2.38$ \\
\hline
\end{tabular}

Note MUPS $=$ Medical unexplained physical symptoms; Chronic $=$ chronic diseases; Psychological $=$ psychological problems and disorders; Locomotor $=$ musculoskeletal symptoms and diseases.

${ }^{*} p<.05 .{ }^{* *} p<.01 .{ }^{* * *} p<.001$, two-tailed. 